\title{
Can Behavioural Economics Contribute to Feminist Discussions?
}

by

Siobhan Austen

Therese Jefferson

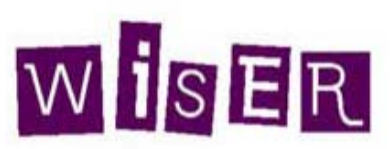

Women in Social \& Economic Research

Working Paper No 53 January 2008

Working Paper Series of Women in Social \& Economic Research Curtin University of Technology

Perth Western Australia http://www.cbs.curtin.edu/wiser 


\section{Can Behavioural Economics Contribute to Feminist Discussions?}

Siobhan Austen

Therese Jefferson

Women in Social \& Economic Research

January 2008

Women in Social and Economic Research can be contacted by:

Phone: +61 892667755

Facsimile: +61 892663026

Email: wiser@cbs.curtin.edu.au

Postal Address: $\quad$ Women in Social \& Economic Research

Curtin Business School

Curtin University of Technology

GPO Box U1987

Perth, Western Australia, 6845 


\begin{abstract}
Feminist and other heterodox economists have provided a detailed and sustained critique of the standard model of an economic decision maker: Homoeconomicus, or rational economic man. The notions of rationality embedded in this model, its asocial and context-free nature, as well as its complete absence of emotion have all drawn extensive and well deserved criticism. Recent developments in behavioural economics provide an opportunity to bring these critiques forward again and to advance the development of more descriptively relevant and inclusive models of decision making. In particular, Daniel Kahneman's Nobel Lecture of 2002 identifies opportunities to move beyond rational framings of decision making; to explore the importance of intuitive thought; and to examine the fundamental importance of contextual factors on the judgments and behaviours of individuals. In doing so, Kahneman's lecture creates avenues for feminist and other heterodox researchers to further advance and disseminate their understandings of decision making.
\end{abstract}

\title{
Introduction
}

Daniel Kahneman’s 2002 Noble prize lecture “Maps of Bounded Rationality: Psychology for Behavioural Economics” brought to the most prominent of public stages a compelling account of the deficiencies of the standard, neo-classical model of decision making (Kahneman, Daniel 2003). He used the lecture to argue that the standard model's emphasis of rational, deliberative, context-independent and emotion-free decision making is descriptively unrealistic. He advocated a reorientation of economics towards the seeking of an understanding of intuitive thought; and of the large role that emotion and context play in determining the intuitive judgments that individuals make.

Kahneman's observations about the deficiencies of the neo-classical model are by no means novel. Important work even within the 'rational choice' tradition has acknowledged the importance of non-material factors and other-regarding motives, 
including those expressed in social norms and moral codes or belief. Numerous 'alternative' models have been created that hold to the notion of a decision making individual (possibly comprised of “multiple-selves”) who consciously takes account of his/her own outcomes but who values both material and non-material outcomes and/or derives utility from the wellbeing of others. Sophisticated versions of these models do not necessarily specify a continuous trade-off between the positive utility gained from material and non-material/other-regarding 'choices’ (see Elster 1996; 1998; Kauffman 1999 for examples). Grief (1994) and North (1991 and 1994) additionally provide models of the cultural and social specificity of individuals' deliberate assessment of their own and others interests.

However, while these approaches convey richer understandings of human decision making than the standard, self-interested, materialistic and asocial models, they still provide only limited opportunities for reflecting the reality of many judgments and decisions. This is because they are still wedded to the idea of individual agents who make deliberative assessments of known costs and benefits. As such, their main deficiency, in our view, is their insufficient acknowledgement of and attention to the nature of intuitive, as opposed to rational, thought and judgment.

Kahneman's lecture helps address this latter and important deficiency in the standard model of decision making. In particular he shifts the focus of decision making analysis away from the various social and economic factors affecting known financial, social and psychic costs and benefits relevant to particular decisions. He directs attention instead to the different contextual circumstances that are likely to cause particular intuitive judgments to be made, regardless of any known or unknown costs 
and benefits. This involves his assertion that most decisions are made intuitively; and that the decision making context largely subsumes the conscious recognition that a decision or judgment is being made. An argument is also made that decision contexts, shaped in part by social and cultural forces, experience, language and relevant personal relationships have important but sometimes unintended and unforeseen causal effects on judgments, decisions and related economic outcomes.

In advancing this argument in his Nobel lecture Kahneman adds substantial weight to a wide range of knowledge claims previously raised by prominent contributors to heterodox economics. For example, Simon has long called for economists to undertake empirical research to understand the construction and effects of decision frames and Hodgson has documented extensive work on the habits and rules that inform decision making that is far from deliberative (see for example Hodgson 1997; Simon 1986). Kahneman's recent work - and the status that has been accorded it via the awarding of the Nobel prize - creates a new opportunity to bring these and other heterodox ideas to the centre of discussions about decision making.

Kahneman's work currently lacks a gender dimension. However, there appears to be a great potential to apply many of his concepts relating to intuitive thought in a manner that extends existing feminist analyses of emotion and context in decision making. In this sense Kahneman's work offers the opportunity to develop models of decision making that are more relevant to women's (and men's) lived experiences. The framework advanced by Kahneman also appears to have the scope to contribute new insights on the sources of observed gender differences in economic behaviour and inequality in economic outcomes. Furthermore, our sense is that Kahneman's 
worldview - and his perception of the role of scientific inquiry - has many similarities with the viewpoints of many feminist economists. As such, there appears to be important opportunities for an ongoing dialogue between feminist and behavioural economics.

The rest of this paper develops these particular themes by exploring Daniel Kahneman's arguments about the importance of intuitive judgments as summarized in the version of his Nobel lecture published in the American Economic Review (Kahneman 2003).

\section{Daniel Kahneman and intuitive thought}

While difficult to measure with precision, there is no doubt that Daniel Kahneman's work has had a considerable impact on economics. Keyword searches in the econlit data base provide a rough and ready guide to the widespread use of terms closely related to work pioneered by Kahneman and his colleagues ${ }^{1}$ : "loss aversion”, 171 returns; "prospect theory", 225 returns; and "framing”, 459 returns. Much of this work is closely related to behavioural economics and behavioural finance which have become growing sub disciplines in their own right. Kahneman and his colleagues's work on loss aversion and framing are particularly well known and these concepts have been applied in a number of settings.

Our sense, however, is that mainstream economists have tended to "cherry pick" aspects of Kahneman's work to focus on those issues that can be readily accommodated by methodological individualism. This is witnessed by the large range

\footnotetext{
${ }^{1}$ Especially Amos Tversky, George Lowenstein and Richard Thaler
} 
of experimental studies which demonstrate the influence of specific heuristics and framings on decision making whilst retaining the notion of an asocial, self-interested decision maker (Dufwenburg, Gachter and Heenig-Schmidt 2007 is an example). Thus far, important additional aspects of Kahneman's work - especially his contributions on intuitive thought - have, to our knowledge, been relatively neglected.

Kahneman's Nobel lecture, which was subsequently revised and published in the American Economic Review, outlined key issues in decision making that he felt were important for economists to consider. As noted in the introduction, in this lecture he clearly sought to emphasise the importance of intuitive thought and the challenges that this poses for economics. Starting with evidence that “....most judgments and most choices are made intuitively...” (Kahneman 2003: 1450), Kahneman proceeded to systematically demolish claims about the descriptive reality of rational-choice models. Ultimately he challenged economists to take up the difficult task of "Incorporating a common sense psychology of the intuitive agent into economic models” (Kahneman 2003: 1470).

\section{Intuitive judgment and accessibility}

In the Nobel lecture Kahneman classifies intuitive judgments as those that come spontaneously to mind without conscious search or computation. Unlike rational decision making, intuitive judgments are effortless, fast and automatic. Intuitive thought is associative, often emotionally charged, governed by habit and difficult to change or modify. It can be associated with poor decision making performance but it is often powerful and accurate. 
The fact that intuitive thought comes to mind spontaneously implies that some thoughts are highly accessible whilst others are not. The accessibility of thoughts is thus a key determinant of intuitive thought and of our subsequent judgments and decisions.

Kahneman provides a framework for assessing the accessibility of different thoughts and judgments, identifying how specific questions or stimuli are relevant. Factors such as the physical characteristics of a stimulus - e.g. its size or loudness - affect accessibility. However, so too do more abstract qualities, such as affective valence, similarity, emotion, surprisingness and mood (Kahneman 2003: 1453). Importantly, many of these latter factors are particularly influenced by the social and cultural context of the individual. As such, Kahneman's analysis identifies an important role for context in determining the nature of intuitive thought and the consequent patterns of economic behaviour and outcomes.

\section{(i) Affective valence}

Affective valence refers to our evaluation of stimuli as 'good' or 'bad'; and of how we are drawn towards "good" objects, whilst we tend to avoid "bad" objects. Kahneman (2003:1453) argues that affective valence is “automatically computed and always accessible” and relates an example where in an experimental setting the affectively charged words 'love' and 'vomit' were attached to assigned tasks. He reports that these labels caused the expected response "within a fraction of a second, well before the meaning of the stimulus was consciously registered...” . 
The high accessibility associated with affective valence gives it a potentially important role in any situation that requires a prospect to be judged as favourable or unfavourable. Labelled an "affect heuristic", it has been shown that people will use their intuitive liking or disliking of a prospect as a substitute for judging a wide range of attributes that might be relevant. Thus, for example, a technology that is intuitively liked is typically judged by the decision maker to have low costs and large benefits (Kahneman 2003: 1463).

Although not discussed by Kahneman, feminists may find it interesting to consider whether 'affective valence' contains a gender dimension. As is well known in heterodox economics, western culture defines a different range of legitimate actions for women and men and it can be argued that women are encultured to have a stronger affective response to the labeling of their behaviour as 'selfish' than men. Kahneman's framework therefore identifies a hypothesis that women will neglect or resist options that have affective labels related to selfishness or self-interest more strongly than men. To the extent that this pattern of gender difference exists, there will also be gender differences in decision making - and these may have significance for inequalities in behaviour and outcomes.

An analysis of the role of affective valence also appears to offer potential insights to how affective labels can be (or are) manipulated to either allow or limit options perceived by women and men. For example, the word "breadwinner" suggests positive associations with fulfilling family responsibilities and legitimate interests in achieving secure, well paid work. In comparison "working mother" suggests a more complex array of dynamics not all of which are favourable or necessarily aligned with 
employment entitlements. The terms such as "good mother" or "bad mother" appear to evoke particularly strong affective responses and are influential in defining appropriate social roles and ideals for women attempting to meet the challenges of motherhood (Johnston, Dierdre J and Debra H Swanson 2006; Robson, Krista 2005).

In sum, affective valence appears to be a useful concept to guide research on the role of culture and cultural symbols in shaping economic behaviour and creating and perpetuating structural differences between women and men.

\section{(ii) Familiar social categories}

Kahneman's work also identifies a role for social categories and prototypes in determining the accessibility of different thoughts: "the mention of familiar social category temporarily increases the accessibility of the traits associated with the category stereotype "(Kahneman 2003: 1454). In a similar vein, Kahneman (2003: 1463) also argues that we tend to simplify decisions or judgments about individuals or events within particular categories by accessing information on a group's prototype, In both cases, this part of Kahneman's work further emphasizes the influence of social structures and contextual factors on intuitive decision making.

As with affective valence, Kahneman argues that social categories are associated with specific decision making short cuts or heuristics, in this case known as prototype heuristics. He acknowledges a range of experiments demonstrating that "whenever we look at a set (ensemble, category) which is sufficiently homogenous to have a prototype, information about the prototype is immediately accessible” (2003: 1463). This has important implications for decision making because the high accessibility of 
prototypes means that prototype heuristics frequently override other relevant attributes of a prospect such as costs, benefits or probabilities.

One example that Kahneman provides of the influence of prototypes on decision making relates to an example where participants were given the following description of a woman named Linda and asked to rate the probability that she was a bank teller and a feminist bank teller:

Linda is 31 years old, single, outspoken and very bright. She majored in philosophy. As a student she was deeply concerned with issues of discrimination and social justice and also participated in antinuclear demonstrations (Kahneman 2003: 1462)

Participants ranked it more probable that Linda was a feminist bank teller than 'just' a bank teller. As feminist bank tellers are a subset of all bank tellers, this conclusion is not consistent with probabilities. However, the conclusion is consistent with judgments made on the basis of representativeness or prototypes: Linda represents a typical feminist bank teller more than she represents a typical bank teller. Other applications of Kahneman's work have shown the importance of gender prototypes in explaining voting patterns (Miller, Dale T, Brian Taylor, and Michelle L Buck 1991), success in completing tasks that are viewed as particularly feminine or masculine(McGill, Ann L 1993) and employment selection decisions (Perry, Elisa L, Alison Davis-Blake, and Carol T Kulik 1994). It has been demonstrated that the existence of gender norms and stereotypes is a significant and international phenomenon “embedded in social and and individual consciousness” (Stephanie Seguino 2007: 1) 
Barbara Reskin (2003) provides a clear policy-relevant example of the risks involved in ignoring these processes. She focuses on the issue of employment discrimination and starts by observing that the 'rational-choice' approach to the analysis of employment discrimination, as evident in Becker’s ‘taste for discrimination’ model (1957), describes employers as consciously attaching an emotional cost to the hiring of e.g. a woman. The employer's employment decision thus is described in rational choice models as intentionally reflecting only the intensity of these felt emotions and other material costs and benefits.

Reskin notes specifically that this approach neglects discrimination that can arise from the unconscious actions of employers and co-workers. In her analysis, which has clear similarities to the ideas advanced by Kahneman, cognitive processes cause us to constantly categorise individuals and attribute to them certain stereotypical behaviours. Thus, whilst our conscious self may find discrimination abhorrent, our unconscious mind may attach certain behaviours to particular individuals because of the group or category we identify them as belonging to. As a result we may think and ultimately act in ways that privilege some individuals and disadvantage others.

The importance of recognizing the influence of intuitive thought is especially highlighted by Reskin when she discusses the implications for the design of antidiscrimination policies. She observes that policies that explicitly provide individuals from minority groups with preferential treatment in, for example, recruitment or promotion, can in fact act to reinforce prevailing stereotypes. In doing so they may exacerbate rather than reduce existing problems of disadvantage. Other policy approaches are more appropriate to respond to the influence of unconscious thought. 
These will directly attempt to challenge and alter our unconscious categorizing of individuals and their attributes, for example, by promoting diversity in work/management groups. To the extent that unconscious thought/ stereotyping is an important determinant of employment discrimination, it may be effective to consider a wider raft of policies than those which might be perceived as preferential.

In sum, the implication of the analyses advanced by both Kahneman and Reskin is that prototypes and, by implication, prevailing stereotypes define (and limit) expected behaviours of others. Our cognitive processes produce particular (and often coordinated) beliefs about groups of people and these beliefs are not simply limited to those actions which are directly relevant to the immediate decision. The evoking of a stereotype makes a range of thoughts immediately accessible and, in doing so, affects the judgments we make. From the perspective of feminist economics one of the clear implications is that gender, as a socially constructed category, is likely to be the basis of a range of prototype heuristics that influence decisions. Thus, without an understanding of social categories, prototypes and widely used stereotypes including their gendered nature - accounts of decision making are unlikely to be adequate and, as Reskin highlights, policy actions are likely to be poorly informed and potentially counterproductive.

\section{(iii) Ambiguity and Uncertainty}

Kahneman also demonstrates how ambiguity can be suppressed by context, with consequent effects on the accessibility of different thoughts. He does this part by recounting an experiment in which participants typically perceived an ambiguous “stimulus” (a handwritten letter B) as a letter (B) when it was surrounded by other 
letters and a number (13) when it was surrounded by other numbers. He thus explained how when ambiguity is suppressed decision making has a tendency to be intuitive. It is only when ambiguity or uncertainty is recognized, people will doubt particular interpretations of a stimulus and deliberative decision making will occur. However, in contexts where uncertainty is inaccessible then judgments will remain intuitive.

Ambiguity and the related linked concept of uncertainty has not been a major focus of feminist scholarship, although discussions of fundamental uncertainty play a prominent role in other heterodox areas of thought such as Post Keynesian economics (Davidson, Paul 1996). So far, however, most discussions of uncertainty relate to people's capacity to predictions of future events (such as discussions of bounded rationality) or the extent to which economic conditions are fundamentally uncertain (again, see Davidson 1996). Kahneman's argument suggests effects of uncertainty that differ from these discussions by emphasizing that in particular contexts we may not even perceive specific uncertainties or ambiguities and thus we can make judgments as though such uncertainties don't exist. Further, this perception doesn't necessarily arise because of our limited computational capacity when making deliberative decisions but occurs because of the context in which the stimulus arises results in an intuitive judgement.

An example of ambiguity of relevance to feminist researchers relates to the importance of context in perceiving and addressing inequitable wages outcomes. For example, a woman receiving relatively low wages who works alongside men receiving relatively high wages might be prompted to question the equity of her 
employer's payment structures. In such a case there may be arguments about the comparability of the different occupational roles performed by men and women but a potential inequity is still relatively easy to identify. However, inequities in the wages of men and women might be less easy to perceive if a woman works in a highly feminised occupation and is surrounded by other women receiving low wages. The situation of child care workers provides an example. While such workers are in highly responsible and important positions, they typically receive low wages. However, as childcare workers are typically employed in a context where all workers receive low wages, it may be difficult for them to perceive an inequity. Is a worker experiencing an inequity if s/he is paid the same wage as all their colleagues? Clearly the answer can be “yes” (Nelson 2006). However, it also seems likely that social context will determine their perception on this question, particularly in the formation of doubt or questions about an appropriate wage level. This may be further exacerbated if norms associated with caring roles are constructed as qualitatively different from those deserving of favourable wages (Nelson 2006: 75-79).

\section{(iv) Emotions}

A further vital part of Kahneman's framework for analyzing intuitive thought is his Kahneman asserts that "The 'hot' states of emotional arousal increase the accessibility of thoughts that relate to the immediate emotion and to the current needs and reduce the accessibility of other thoughts.” (Kahneman 2003:1454) An important implication is that when we associate an action or event with particular either highly positive or negative emotions we tend to block out other information that is relevant to an associated decision. For example, if we associate decisions about divorce with the emotional experiences tied up with the communication of this 'event' to children then 
the accessibility of relevant information on, say, long term financial and health issues is likely to be reduced. In a related vein, Kahneman cites research by Lowewenstein and Elster and notes how the use of emotionally arousing stimuli in marketing strategies increase the accessibility of some thoughts and suppress the accessibility of others. People are apparently less sensitive to variations in probability when a potential outcome is emotionally loaded (for example a kiss) rather than a purely monetary outcome.

Generally Kahneman (2003) argues that we cannot understand preferences without understanding the psychology of emotions; preferences caused by emotion may not be internally coherent or even "reasonable”; and, as a result, a descriptively realistic portrayal of decision making will require account be taken of the emotions attached to particular decisions. As such, although he does not directly engage in the core debate between feminist and mainstream economists about the significance of emotions and whether an area of social research such as economics can be legitimately constructed without recognizing the significance of emotions, Kahneman's research clearly adds support for the feminist stance (see England 1993; Harding 1987; Himmelweit 1995; Lawson 1999; Nelson 2003a;b). Furthermore, his analysis of the role of emotions in determining thought accessibility provide insights into some of the effects of emotion on decision making and, together with other behavioural writings, some clues as to potential methods for examining these effects. 


\section{Kahneman's applications}

\section{(i) Loss aversion and endowment effects}

In the Nobel lecture Kahneman briefly elaborated on some of his own applications of the concepts relating to accessibility. These include his well known analyses of loss aversion, endowment effects and framing and they serve to also highlight potential contributions from behavioural economics to feminist discussions.

As has been documented in numerous experiments, decision makers typically associate prospective losses with a much greater negative change in utility than they associate equivalent prospective gains with a positive utility change. The negative affective nature of the label 'loss' is partly responsible for this pattern. Its consequences include a propensity for individuals to engage in behaviours that avoid the prospect of a loss (e.g. we tend to favour options that include some prospect of a gain over options that deliver certain losses even in circumstances where expected returns on the favoured option are relatively low).

Kahneman also demonstrates that decision makers typically focus on short term changes in states rather than final outcomes, as emotions are triggered by change. That is, our attention tends to be drawn especially to the possibility and magnitude of potential financial losses - and our anticipated emotional response to these changes rather than to final total levels of expected income.

Particular emphasis is given by Kahneman to the reference points from which evaluations of gains or losses are made. In Kahneman's analysis, the individual's existing income or wealth position (i.e. his/her endowment point) becomes 
fundamental to determining whether a prospective loss or a prospective gain will be perceived. In turn, variations in pattern of judgments are predicted to occur in accordance with the initial structure of endowments.

This particular aspect of Kahneman’s work appears to also have gender implications that are worthy of research. In a social and economic context, where there are systematic gender differences in initial endowments of income, education, property and other assets, reference points and, thus, judgments of equivalent prospects are likely to differ between women and men. In the financial sphere, for example, women appear to 'decide' to accumulate relatively "low risk" investment portfolios (Bajtelsmit, Bernasek, and Jianakoplos 1999; Bajtelsmit and VanDerhei 1997; Jianakolpos and Bernasek 1998; Sunden and Surette 1998). Rational choice explanations for this focus on the notion that women are inherently more risk averse then men. One alternative possibility, identified in Kahneman's work - and also apparent in feminist understandings of the issue - is that gender differences in investment portfolios result, in part at least, from differences in initial endowments. That is, from both feminist and behavioural economics perspectives endowments, rather than sex, are likely to be a key causal influence in investment decisions.

\section{(ii) Framing}

Framing effects demonstrate the way in which preferences vary according to the way in which objectively identical outcomes are described. Framing is often discussed with reference to Kahneman’s “Asian disease” experiment, in which two objectively identical predictions of fatalities from a pandemic are presented to participants. A significant majority of participants prefer an option that expresses outcomes in terms 
of potential gains rather than losses of life (Kahneman, Daniel and Amos Tversky 1984).

The potential for framing effects to violate the tenets of rational decision making, particularly invariance, have been widely demonstrated. Current debates tend to focus on refinements of research methods and procedures for testing framing effects rather than on debates about their existence (Druckman, James N. 2001).

From the perspective of feminist economics, another of Kahneman's examples is perhaps more relevant. He summarises an experiment on reactions to alternatively framed policy choices conducted by Thomas Schelling.

Schelling reports asking his students to evaluate a tax policy that would allow a larger child exemption to the rich than the poor. Not surprisingly, his students found this proposal outrageous. Schelling then pointed out the default case in the standard tax table is a childless family, with special adjustments for families with children, and led his class to agree that the existing tax schedule could be rewritten with a family with two children as a default case. In this formulation, childless families would pay a surcharge. Should this surcharge be as large for the poor as for the rich? Of course not. The two versions of the question about how to treat the rich and poor both trigger intuitive preference for protecting the poor, but these preferences are incoherent. Schelling's problem highlights an important point. Framing effects are not a laboratory curiosity but a ubiquitous reality. The tax table must be framed one way or another and each frame will increase the accessibility of some responses and 
make other responses less likely (Kahneman 2003; see also McCaffery, Edward J. and Jonathan Baron 2004)

This type of analysis, coming as it does from the desks of two Nobel laureates, bolsters the arguments advanced by feminist economists engaged in "gender impact assessments” of public policy. Feminists have argued over a long period of time for attention to be paid to the framing of public policy measures and the particular consequences of this for gendered outcomes (Susan Himmelweit 2002). In addition, there is some evidence that women's and men's varying experiences can lead them to interpret particular decision frames in different ways. Thus alternative framings of tax issues have been shown to elicit different responses from men and women (Hasseldine, John and Peggy A. Hite 2003).

\section{A Case Study: Extending our insights from small scale research projects}

We can add a further perspective on the relevance of Kahneman's work that is drawn from one of our own research projects: a study of women's capacity to save for retirement. This study was prompted by broad recognition that Australia’s system of compulsory saving retirement is structured in a manner which works relatively well for people with patterns of well paid and long term continuous employment. Women are, however, over represented in sectors of the workforce with relatively low pay and broken patterns of employment.

In a qualitative study we interviewed thirty women to gain insights into their perceptions about their capacity to save for retirement (Jefferson 2007; Jefferson, Austen and Preston 2005). Many of our findings were consistent with previous studies 
and identified low incomes and comparatively poor access to relevant information and resources about retirement planning as important contributors to low savings accumulations. However, a substantial feature of the interview data - and one that has particular relevance to this paper's discussion - was the extent to which many women described processes for saving for retirement that were not linked to any specific planned outcomes or goals, nor indeed to any apparent deliberative decision making.

Supporting Kahneman's conclusions on the relatively low importance of deliberative decision making, the financial processes in many of the households we studied appeared to be motivated by a desire to actually preclude the need for constant, deliberative decision making. For example, some households "automatically" allocated income from one source to specific accounts or purposes (often electronically) and this process was not regularly reviewed, even if it significantly affected major financial outcomes such as the length of time taken to pay off a mortgage. The study also identified how decision making processes relating to household finances were significantly affected by the emotional aspects of allocating household resources among household members (including children). A particularly touching example of this involved one woman's wish not to save for the future because of her husband's unfavourable health prognosis: no matter how rational, saving for a future without him was too awful to consider. Gender norms (or prototypes) in many cases gave a low priority to women's independent earnings and saving and for many women this view was reinforced through labour force policies earlier in their careers: “Of course you weren’t allowed to be married in my day, as a nurse...”. There was also a relative lack of social norms (or prototypes) relating to women's independent savings goals and strategies, with some women perceiving a 
lack of financial information relevant to their situation: "I find that investing is... more geared to the men, you know, the language and things like that...”

Overall we were struck by the extent to which many women described savings outcomes which appeared to reflect particular features of their social context rather than deliberative decision making and choice. At the conclusion of that particular study, we concluded that traditional economic models of decision making, which omit issues such as emotions, prototypes and uncertainty, fail to capture the reality of many women's lived experiences and are a poor guide to understanding their situations and to the design of appropriate policy responses.

We now face an ongoing challenge to further develop our arguments within a framework that generates insights and policy recommendations that transcend the individual stories of the women that we spoke to. Women's savings patterns are an important, if neglected, area of retirement income frameworks. Systematic research together with language and rhetoric that both demonstrate women's experiences and have legitimacy amongst colleagues and policy makers may play a role in securing policy reforms that address women's access to resources in later life.

\section{Kahneman's work, feminist philosophies and future directions}

The final part of this paper turns from the practical examples of the potential links between feminist economics and behavioural economics to some broad philosophical issues with a bearing on our argument. Often prompted by Tony Lawson's ontological theory, heterodox schools of thought have recently engaged in debates about the philosophical foundations of economics. Feminist scholars have played an influential 
role in this debate, particularly in identifying the socially constructed nature of knowledge and the challenges inherent in claims that appeals to reality can be a final arbiter among competing representations of social phenomena (Druscilla Barker 2003; Sandra Harding 1999; 2003; Tony Lawson, 1999; 2003; Julie Nelson 2003b; Fabienne Peter 2003; Druscilla Barker and Edith Kuiper 2003) ${ }^{2}$. Here we draw attention to the particular contributions made by Julie Nelson and, especially, the apparent consistency in the worldview espoused in her arguments and those that appear to underpin Kahneman's research and methods.

Nelson identifies Alfred Whitehead's process theory as particularly relevant to feminist scholarship and this emphasizes the importance of change and of experience or feelings.

....the real 'stuff' of reality is not...matter (objects taking up space), but rather events or experience...(Nelson 2003c: 136, emphasis original)

In comparison, Kahneman (2003: 1457) describes the standard model of decision making as "descriptively sterile" on the basis that it considers a reality made up of only final (wealth) states and “completely ignores feelings.”

Nelson has previously argued that emotion is part of economic agents' reality and that to ignore it is to neglect and bias the outcomes of analysis:

Unless "emotion" - and, indeed, "value” itself - are present in the core of what we believe about how the world works, care and emotion will never overcome their status as mere add-ons (Nelson, 2003b:110, emphasis in the original).

\footnotetext{
${ }^{2}$ Austen and Jefferson (2006) provide an overview
} 
Similarly, Kahneman (2003: 1457) asserts that "utility cannot be divorced from emotion.”

Process theory also emphasizes the importance of time and context:

Time is extremely important...: what we have, at any moment, is new events or happenings that are related to past happenings and that create the basis for events in the next moment. (Nelson 2003c: 136)

In comparison, Kahneman (2003: 1455) delivers a strident critique of the notion in standard choice theory that the "utility of decision outcomes is...determined by the final state of endowment, and is therefore reference independent.”

We acknowledge that the suggested link between Nelson's and Kahneman's apparent worldviews is based on statements which appear to have similar meanings. We are especially cautious about the comparisons between Kahneman's work and process theory as we have been unable to identify any acknowledgement of Whitehead or process theory in Kahneman's work. That said, the apparent consistency between Nelson's insights, process theory and Kahneman's work suggest to us that there may be a broad philosophical basis for pursuing collaborations between feminist and areas of behavioural economics that generate insights into the importance of gender as a key element of our decision making contexts.

We suspect that many feminists would support the research agenda outlined by Kahneman in the closing section of his Nobel lecture. Kahneman emphasized the need for further work on understanding “what would an impulsive agent do?”; 
whether "the intuitively attractive judgment or course of action is in conflict with a rule the agent would endorse?"; and "how likely is it in the situation at hand that the relevant rule will come to mind in time to override intuition?” (Kahneman 2003: 1469). The latter part of this agenda, which steps away from the rational choice presumption that each individual's revealed actions are unchallengeable - and implies a potential role for research that improves our understanding of decision making, is in line feminist understandings. For example, we can compare the above statements from Kahneman and another of Nelson's expressed viewpoints:

Because of the limitations of our senses and our processing abilities, we develop, in everyday life, habits and filters that restrict our perceptions of our lived moments. Scientific thought, as inquiry, involves extending our perceptions and refining our powers of reflection, and as such is both part of experience and a purposive seeking to understand and better our lives through (extended) experiences (Nelson 2003b: 137)

\section{Conclusion}

Throughout this paper we have argued that there appears to be a basic level of consistency between the research agendas of feminist economics and behavioural economics as detailed by Kahneman in his Nobel Prize lecture. While many of Kahneman’s insights have a relatively long history in both economic heterodoxy and feminis, we have identified Kahneman's work as providing a set of tools that can facilitate investigations of issues of importance to feminist scholarship. This appears particularl relevant to research that examines the role of emotions and context in the determination economic judgments and behaviour. Our conclusion is to broadly agree with Kahneman's claims that his model of intuitive thought, with its emphasis on 
accessibility, appears to be "simple and easy to apply, and likely to yield hypotheses that are generally plausible and often surprising”. In addition to Kahneman's arguments, however, we claim that feminists can play an important role in integrating gender analyses into behavioural studies of decision making. Kahneman's rhetorical devices have achieved legitimacy among many within the broader economics community, and that this provides a potential basis for further advancing ideas long established in heterodox economics generally and feminist economics in particular.

\section{References}

Austen, Siobhan and Therese Jefferson. 2006. "Comparing Responses to Critical Realism”, Journal of Economic Methodology, 13:2, pp. 257-282

Bajtelsmit, Vickie L, Alexandra Bernasek, and Nancy A Jianakoplos. 1999. "Gender differences in defined contribution pension decisions." Financial Services Review, 8:1, pp. 1-10.

Bajtelsmit, Vickie L and Jack L VanDerhei. 1997. "Risk aversion and pension investment choices," in Positioning Pensions for the Twenty-first Century. Michael S Gordon and Olivia S Mitchell eds. Philadelphia: University of Pennsylvania Press, pp. 47-66.

Barker, Druscilla K. 2003. "Emancipatory for whom? A comment on critical realism." Feminist Economics, 9:1, pp. 103-08.

Becker, Gary. 1957. The Economics of Discrimination. Chicago: University of Chicago Press.

Davidson, Paul. 1996. "Reality and economic theory." Journal of Post Keynesian Economics, 18:4, pp. 479-508.

Druckman, James N. 2001. "Evaluating framing effects." Journal of Economic Psychology, 22:1, pp. 91-101.

Dufwenberg, Martin. Simon Gächter and Heike Hennig-Schmidt. 2007. “The Framing of Games and the Psychology of Play”, accessed on November 92007 at http://www.u.arizona.edu/ martind1/Papers-Documents/tfogatpop.pdf

Elster, Jon. 1996. "Rationality and the emotions." The Economic Journal, 106:438, pp. 1386 - 97. 
Elster, Jon. 1998. "Emotions and economic theory." Journal of Economic Literature, 36:1, pp. 47-74.

England, Paula. 1993. "The separative self: Androcentric bias in neoclassical assumptions," in Beyond Economic Man. Marianne Ferber and Julie A Nelson eds. Chicago: University of Chicago Press, pp. 37-53.

Grief, Avner. 1994. "Cultural beliefs and the organization of society: A historical and theoretical reflection on collectivist and individualist societies.” Journal of Political Economy, 102:5, pp. 912-950

Harding, Sandra. 1987. "Is there a feminist method," in Feminism and Methodology. Sandra Harding ed. Bloomington: Indiana University Press, pp. 1-14.

Harding, Sandra. 1999. "The case for strategic realism: A response to Tony Lawson." Feminist Economics, 5:2, pp. 127-33.

Harding, Sandra. 2003. "Representing reality: The critical realism project." Feminist Economics, 9:1, pp. 151-59.

Hasseldine, John and Peggy A. Hite. 2003. "Framing, gender and tax compliance." Journal of Economic Psychology, 24:4, pp. 517-33.

Himmelweit, Susan. 1995. "The discovery of unpaid work: The social consequences of the expansion of 'work'." Feminist Economics, 1:2, pp. 1-19.

Himmelweit, Susan. 2002. "Making visible the hidden economy: The case for gender impact analysis of economic policy." Feminist Economics, 8:1, pp. 40-70.

Hodgson, Geoffrey M. 1997. "The ubiquity of habits and rules," in Recent Developments in Institutional Economics. Geoffrey $\mathrm{M}$ Hodgson ed. Cheltenham, UK: Edward Elgar, pp. 379-400.

Jefferson, Therese. 2007. "Two studies of women's retirement incomes in Australia: assessing some outcomes of pluralism in economic research." Cambridge Journal of Economics, 31:3, pp. 363-78.

Jefferson, Therese, Siobhan Austen, and Alison Preston. 2005. "Adjusting the Focus: Perceptions of Life, Work and Saving for Retirement." Women's Economic Policy Analysis Unit http://www.cbs.curtin.edu.au/business/research/researchunits/women-in-social-and-economic-research: Perth, Australia.

Jianakolpos, Nancy A and Alexandra Bernasek 1998. "Are women more risk averse?" Economic Inquiry, 36:4, pp. 620-30.

Johnston, Dierdre J and Debra H Swanson. 2006. "Constructing the "Good Mother": Teh experience of mothering ideologies by work status." Sex Roles, 54, pp. 509-19. 
Kauffman, Bruce E. 1999. "Emotional arousal as a source of bounded rationality." Journal of Economic Behavior and Organization, 38, pp. 135-44.

Kahneman, Daniel. 2003. "A perspective on judgement and choice: Mapping bounded rationality." American Psychologist, 58:9, pp. 697-720.

Kahneman, Daniel and Amos Tversky. 1984. "Choices, values, and frames." American Psychologist, 39:4, pp. 341-50.

Lawson, Tony. 1999. "Feminism, realism and universalism." Feminist Economics, 5:2, pp. 25-59.

Lawson, Tony. 2003. "Ontology and feminist theorizing." Feminist Economics, 9:1, pp. 119-50.

McCaffery, Edward J. and Jonathan Baron. 2004. "Framing and taxation: Evaluation of tax policies involving household composition." Journal of Economic Psychology, 25:6, pp. 679-705.

McGill, Ann L. 1993. "Selection of a causal background: Role of expectation versus feature mutability." Journal of Personality and Social Psychology, 64:5, pp. 701-07.

Miller, Dale T, Brian Taylor, and Michelle L Buck. 1991. "Gender gaps: who needs to be explained?" Journal of Personality and Social Psychology, 61:1, pp. 512.

Nelson, Julie A. 2003a. "Confronting the science/value split: notes on feminist economics, institutionalism, pragmatism and process thought." Cambridge Journal of Economics, 27:1, pp. 49-64.

Nelson, Julie A. 2003b. "Once more with feeling: Feminist economics and the ontological question." Feminist Economics, 9:1, pp. 109-18.

Nelson, Julie A. 2003c. 'How did "the moral" get split from "the economic". in Drucilla Barker and Edith Kuiper (eds). Toward a Feminist Philosophy of Economics. New York: Routledge, pp. 134-142.

Nelson, Julie A. 2006. Economics for Humans. Chicago: University of Chicago Press.

North, Douglas. 1991. “Institutions.” Journal of Economic Perspectives, 5:1, pp.97112

North, Douglas. 1994. "Economic performance through time.” American Economic Review, 84: 3. pp.359-368

Peter, Fabienne. 2003. "Critical realism, feminist epistemology, and the emancipatory potential of science: A comment on Lawson and Harding." Feminist Economics, 9:1, pp. 93-101. 
Perry, Elisa L, Alison Davis-Blake, and Carol T Kulik. 1994. "Explaining genderbased selection decisions: A synthesis of contextual and cognitive approaches." Academy of Management Review, 19:4, pp. 786-820.

Robson, Krista. 2005. "'Canada's most notorious bad mother": The newspaper coverage of the Jordan Heikamp inquest." the Canadian Review of Sociology adn Anthropology, 42:2, pp. 217-32.

Reskin, Barbara. 2003. "Rethinking employment discrimination and its remedies.” in The New Economic Sociology. Mauro Guillen. Randall Collins, Paula England and Marshall Meyer eds. New York. Russell Sage, pp.218-244.

Seguino, Stephanie . 2007. "Plus ça change? Evidence on global trends in gender norms and stereotypes.” Feminist Economics, 13(2):1-28.

Simon, Herbert A. 1986. "Rationality and psychology in economics." The Journal of Business (1986-1998), 59:4, pp. s209-s24.

Sunden, Annika E. and Brian J. Surette. 1998. "Gender differences in the allocation of assets in retirement savings plans." The American Economic Review, 88:2, pp. $207-11$. 